\title{
MORFOLOGIA POLÍNICA DO GÊNERO PLUCHEA CASS. (ASTERACEAE), NO RIO GRANDE DO SUL, BRASIL
}

\author{
RODRIGO RODRIGUES CANCELLI \\ Laboratório de Palinologia, ULBRA, Av. Miguel Tostes, 101,92420-280, Canoas, RS, Brasil.rodrigocancelli@ibest.com.br \\ ANGELO ALBERTO SCHNEIDER \\ Departamento de Botânica, UFRGS, Av. Bento Gonçalves, 9500, 91540-970, Porto Alegre, RS, Brasil. \\ angeloschneider@yahoo.com.br \\ SORAIA GIRARDI BAUERMANN \\ Laboratório de Palinologia, ULBRA, Av. Miguel Tostes,101, 92420-280, Canoas, RS, Brasil.soraia.bauermann@ulbra.br
}

\begin{abstract}
RESUMO - Este trabalho apresenta os resultados obtidos a partir do estudo morfológico em grãos de pólen do gênero Pluchea. Este gênero está representado no Rio Grande do Sul por Pluchea laxiflora Hook. \& Arn. ex Baker, Pluchea oblongifolia DC. e Pluchea sagittalis (Lam.) Cabr. Plantas deste gênero podem variar de ervas a subarbustos, podendo habitar desde campos úmidos até locais arenosos. Foram estabelecidos três padrões polínicos baseados nas diferenças da estrutura da exina e no tamanho da ornamentação e da cava. Dados sobre o ambiente, ocorrência das respectivas plantas, assim como aspectos da origem da família Asteraceae e a taxonomia da tribo Plucheeae, são aqui discutidos.
\end{abstract}

Palavras-chave: Palinotaxonomia, Asteraceae, Pluchea, morfologia polínica.

ABSTRACT - POLLINIC MORPHOLOGY OF THE GENUS PLUCHEA CASS. (ASTERACEAE), FROM THE RIO GRANDE DO SUL, BRAZIL. This work presents the results obtained from morphological studies on pollen grains of Pluchea. This genus is represented in the state of Rio Grande do Sul (Brazil) by Pluchea laxiflora Hook. \& Arn. ex Baker, Pluchea oblongifolia DC. and Pluchea sagittalis (Lam.) Cabr. Plants of this genus can vary from herbs to shrubs and inhabit since humid fields until sandy places. Three pollinic patterns were established based on differences of the exine structure, and the size of the ornamentation and the cavea. Data about the environment and/or occurrence of the respective plants as well as the originating aspects of the Asteraceae family and the tribe taxomomy are discussed herein.

Key words: Palinotaxonomy, Asteraceae, Pluchea, pollinic morphology.

\section{INTRODUÇÃO}

Asteraceae é considerada a maior família de Angiospermas, compreendendo 1.535 gêneros e cerca de 23 mil espécies, distribuídas em três subfamílias e 17 tribos (Bremer, 1994). Devido ao seu extraordinário poder de adaptação ambiental, podem ser encontradas nos mais diversos hábitats e em diferentes regiões climáticas (tropicais, subtropicais e temperadas). Outro fator importante para seu sucesso biológico é sua grande capacidade de dispersão, devido à presença de pápus plumosos, apêndices, estruturas de aderência e metabólitos secundários (Venable \& Levin, 1983).

As Asterales (Asteraceae, Campanulaceae, Goodneniaceae e Menyanthaceae) têm sua origem geográfica relacionada ao Gondwana Ocidental e seu registro polínico fóssil data do Cretáceo. O posterior isolamento da América do Sul, ocorrido no Eoceno, confinou parte das Asteraceae a este continente (Bremer \& Gustafsson, 1997), que possui, atualmente, cerca de $30 \%$ da diversidade genérica da família e 50\% da diversidade específica (Bremer, 1994; Hind, 1993). As tribos melhores representadas são: Astereae, Barnadesieae, Eupatorieae, Gnaphalineae, Heliantheae, Libeae, Mutisieae, Plucheeae e Vernonieae. A alta representatividade de Barnadesieae, tribo considerada basal na família Asteraceae, assume caráter relevante, já que a origem geográfica de um grupo taxonômico pode ser suposta a partir da correlação entre a distribuição dos subgrupos e a filogenia dos mesmos. No sul do Brasil, a flora asterológica é bastante densa e de alta diversidade específica, com tendência a uma melhor representatividade das tribos Astereae, Inuleae, Helenieae e Mutisieae, nas quais predominam espécies microtérmicas (Matzenbacher, 2003). 
Dezenove tribos foram reconhecidas inicialmente dentro da família Asteraceae, com o gênero Pluchea incluído na tribo Inuleae (Dalpiaz \& Ritter, 1998). Esta tribo foi alvo de várias revisões, com base em estudos de morfologia polínica, fitoquímica e citologia. Características como a esporoderme dos grãos de pólen, entre outras, permitiram o estabelecimento de três subtribos: Inulinae, Gnaphaliinae e Anthrixiinae (Merxmüller et al., 1977). De acordo com a classificação mais usual (Anderberg, 1989), Inuleae (sensu lato) foi reorganizada em três tribos: Inuleae Cass. sensu stricto, Plucheae Anderb. e Gnaphalieae Benth. Estudos cladísticos recentes consideraram a família Asteraceae constituída por onze subfamílias, estando o gênero Pluchea abrigado em Asteroideae (Stevens, 2001).

Pluchea apresenta 80 espécies de ampla distribuição geográfica, sendo três delas citadas para o Rio Grande do Sul: Pluchea laxiflora Hook. \& Arn. ex Baker; Pluchea oblongifolia DC. e Pluchea sagittalis (Lam.) Cabr., esta última conhecida popularmente como quitoco, arnica ou madre cravo, e usada na medicina popular como carminativa, estomática, antiespasmódica e para afecções do fígado e vesícula biliar (Bürguer, 1995).

Poucos trabalhos se dedicaram à palinotaxonomia de Asteraceae no Brasil (Moreira, 1969; Salgado-Labouriau, 1973; Melhem et al., 1979, 2003; Mendonça \& Gonçalves-Esteves, 2000; Peçanha et al., 2001; Mendonça et al., 2002, 2003). Este trabalho tem por objetivo apresentar dados inéditos sobre morfologia polínica de Pluchea oblongifolia e Pluchea laxiflora, além de fornecer subsídios para estudos taxonômicos e paleoambientais. Informações sobre o hábitat e outras relações biológicas também são apresentadas, assim como uma breve descrição morfológica das espécies.

\section{MATERIAL E MÉTODOS}

O material botânico para as preparações palinológicas foi retirado de exsicatas provenientes do Herbário do Instituto de Ciências Naturais da Universidade Federal do Rio Grande do Sul (ICN). O material testemunho possui as seguintes numerações: Pluchea laxiflora Hook. \& Arn. ex Baker (ICN106390 e 133893); Pluchea oblongifolia DC. (ICN-106391 e 106422) e Pluchea sagittalis (Lam.) Cabr. (ICN-106425 e 94855).

Para a preparação dos grãos de pólen foi utilizado o método de acetólise segundo Erdtman (1952) e para a montagem das lâminas permanentes foi utilizada gelatina-glicerinada. As lâminas palinológicas encontram-se depositadas na Palinoteca do Laboratório de Palinologia da Universidade Luterana do Brasil (ULBRA, Canoas), com as seguintes numerações: Pluchea laxiflora Hook. \& Arn. ex Baker, P0160a-e; Pluchea oblongifolia DC., P-0159a-e; Pluchea sagittalis (Lam.) Cabr., P-0161a-e.

As amostras para Microscópio Eletrônico de Varredura (MEV) foram separadas antes da acetólise e conservadas em álcool $70^{\circ} \mathrm{GL}$. Uma gota do material em suspensão foi pingada na superfície de cada suporte (stubs), metalizados com ouro/ paládio em um evaporador de metais após a secagem. As imagens eletrônicas foram obtidas no Centro de Microscopia Eletrônica e Microanálise da ULBRA.

As observações das lâminas polínicas foram feitas em microscópio óptico (Leica) e as mensurações realizadas no máximo uma semana após a acetólise. Foram medidos 25 grãos em vista equatorial para a determinação do diâmetro polar (DP), diâmetro equatorial (DE), altura da ornamentação e espessura da exina. Para a quantificação do índice de área polar, do tamanho da cava e dos colpos, foram medidos 10 grãos de pólen na região do mesocolpo, em vista polar.

Nas descrições polínicas, os caracteres são apresentados na seguinte ordem: classe de tamanho (diâmetro maior), forma (unidade polínica, polaridade e simetria), razão diâmetro polar pelo diâmetro equatorial (P/E), âmbito, descrição das aberturas (número, posição e caráter), da exina (espessura) e da ornamentação.

O tamanho do grão de pólen, a espessura da exina e a altura da ornamentação, do colpo e da cava estão representados pelas médias aritméticas de suas respectivas medidas. Os grãos de pólen são ilustrados por fotomicrografias de microscopia óptica e eletrônica de varredura. Todas as ilustrações, com exceção das fotomicrografias em MEV, foram apresentadas em aumento de 1.000x. Para a descrição palinológica dos táxons, foi utilizada a nomenclatura de Punt etal.(1994).

\section{ASPECTOS BOTÂNICOS}

O gênero Pluchea Cass. inclui ervas perenes ou arbustos, com caules freqüentemente alados; folhas alternas, glanduloso-pontuadas, margem denteada a serreada, inteiras e, geralmente, decurrentes. Capítulos solitários ou dispostos em corimbos terminais, heterógamos, com flores multisseriadas, pistiladas férteis, centrais multisseriadas e funcionalmente estaminadas. Invólucro campanulado, com até 10 séries de brácteas paleáceas, receptáculo plano e glabro. Corola com flor pistilada filiforme. Aquênio 4-5 ângulos; pápus alongado e filiforme com uma única série de cerdas capilares.

Pluchea oblongifolia DC. é um subarbusto ereto com até $1,5 \mathrm{~m}$ de altura, caule roliço, não alado, robusto e piloso; folhas alternas, sésseis, oblongo-lanceoladas ou elípticas, denteadas e não decurrentes. Capítulos numerosos em corimbos densos, terminais e com altura maior que a largura; habita preferencialmente locais úmidos; fenologia: floresce de fevereiro a maio. Segundo Dalpiaz \& Ritter (1998), ocorre em Minas Gerais, São Paulo e Rio de Janeiro. No Rio Grande do Sul, ocorre com maior freqüência no Litoral e na Depressão Central, mas também nos Campos de Cima da Serra e na Encosta Inferior do Nordeste.

Pluchea sagittalis (Lam.) Cabr. é uma erva ou arbusto aromático com odor suave característico e altura variando de 0,30 a 2,0 m; caule robusto, foliáceo, alado e piloso. Folhas sésseis oblongo-laceoladas, levemente denteadas e com base decurrente. Capítulos discóides de largura maior que a altura em densas panículas de corimbos; habita preferencialmente campos úmidos e banhados, podendo ocorrer em locais 
arenosos ou comportar-se como ruderal; fenologia: floresce de outubro a julho, preferencialmente em março e abril. Segundo Dalpiaz \& Ritter (1998), ocorre em todo o Brasil. No Rio Grande do Sul, ocorre em várias regiões, sendo mais freqüente na Depressão Central.

Pluchea laxiflora Hook. \& Arn. ex Baker é um subarbusto ereto com até 2,0 $\mathrm{m}$ de altura; caule alado e piloso; folhas sésseis, alternas, elípticas, base decurrente e ápice agudo. Capítulos numerosos em corimbos laxos com altura maior que a largura; habita preferencialmente campos úmidos próximos a várzeas e em beira de estradas; fenologia: floresce de dezembro a maio com ápice em janeiro. Segundo Dalpiaz \& Ritter, (1998), ocorre em São Paulo e Santa Catarina. No Rio Grande do Sul aparece com maior freqüência no litoral e na encosta sul da Serra do Sudeste.Também ocorre na Depressão Central e nos Campos de Cima da Serra.

\section{MORFOLOGIA POLÍNICA}

Palinologicamente, a família Asteraceae caracteriza-se por apresentar grãos de pólen em sua maioria isopolares, radiossimétricos, geralmente oblato-esferoidais, às vezes prolato-esferoidais, sempre próximo da forma esférica, majoritariamente tricolporados ou triporados, ós (endoabertura) sempre lalongado arredondados ou afilados. Exina espessa, com corte óptico bem característico, sexina tegilada (tectada) com espinhos ou espículos, raramente sem espinhos ou reticulada. Columelas separando a nexina da sexina (SalgadoLaboriau, 1983). As características diagnósticas diferenciais para as espécies de Pluchea ocorrentes no Rio Grande do Sul estão apresentadas na Quadro 1.

\section{Pluchea oblongifolia DC.}

(Figura 1A-H)

Descrição. Grãos de pólen médios, isopolares, radiossimétricos, prolato-esferoidais, âmbito circular a subtriangular, tricolporados e espinhosos. Aberturas: três colporos bem visíveis, colpos grandes [largura 13,5 $\mu \mathrm{m}$ (12$15 \mu \mathrm{m})$, comprimento $18,9 \mu \mathrm{m}(16-21 \mu \mathrm{m})]$, de margens lisas, pontas arredondadas e endoaberturas lalongadas. Exina espessa $[2,1 \mu \mathrm{m}(2-2,5 \mu \mathrm{m})]$, sexina maior que a nexina,

Quadro 1. Características diagnósticas para identificação das espécies de Pluchea.

Chart 1. Diagnostic characteristics for identifying Pluchea species.

\begin{tabular}{|lc|}
\hline $\begin{array}{l}\text { 1. Grãos de pólen com endosexina em } 2 \text { séries, } \\
\text { espinhos ca. } 7,0 \mu \mathrm{m} \text { de altura, apresentando }\end{array}$ \\
$\begin{array}{l}\text { sexina separada da nexina por uma cava com } \\
5 \mu \mathrm{m}\end{array}$ & P. laxiflora \\
1'. Grãos de pólen com endosexina simples e & \\
espinhos com ca. $5 \mu \mathrm{m}$, apresentando sexina & \\
separada da nexina por uma cava menor do que & \\
$5 \mu \mathrm{m}$ & 2 \\
\hline $\begin{array}{l}\text { 2. Grãos de pólen apresentado sexina separada da } \\
\text { nexina por uma cava com } 2 \mu \mathrm{m}\end{array}$ & P. sagittalis \\
$\begin{array}{l}\text { 2. Grãos de pólen apresentando uma pequena } \\
\text { cava menor que } 1 \mu \mathrm{m}\end{array}$ & \\
\hline
\end{tabular}

separadas por uma cava pequena que aumenta de altura na região mediana do mesocolpo. Em MEV teto subpsilado e punctado. Sexina espinhosa, tectada com perfurações, endosexina e ectosexina separadas por columelas digitadas, mais altas na base dos espinhos. Ornamentação constituída por espinhos grandes $[5,44 \mu \mathrm{m}(5-7 \mu \mathrm{m})]$ de bases largas, com perfurações, ápices arredondados, providos de pequenas cavidades. Nexina lisa.

Dimensões. DP: 35,52 $\mu \mathrm{m}(31-41 \mu \mathrm{m})$; DE: 34,98 $\mu \mathrm{m}(32-41 \mu \mathrm{m})$; Razão DP/DE: 1,01.

\section{Pluchea sagittalis (Lam.) Cabr.} (Figura 2A-H)

Descrição. Grãos de pólen médios, isopolares, radiossimétricos, prolato-esferoidais, âmbito circular, subtriangulares, tricolporados e espinhosos. Aberturas: três colporos bem visíveis, colpos grandes [largura 10,2 $\mu \mathrm{m}$ (9-12 $\mu \mathrm{m})$, comprimento do colpo: 19,3 $\mu \mathrm{m}(18-20 \mu \mathrm{m})]$, de margens lisas, pontas arredondadas, endoabertura lalongada. Exina: fina $[1 \mu \mathrm{m}(1 \mu \mathrm{m})]$ sexina maior que a nexina, separadas por uma cava que aumenta de altura na região mediana do mesocolpo. Em MEV teto subpsilado e punctado. Sexina: tectada, endosexina e ectosexina separadas por columelas digitadas mais altas na base dos espinhos. Ornamentação constituída por espinhos grandes [5,04 $\mu \mathrm{m}(4-7 \mu \mathrm{m})] \mathrm{e}$ robustos de bases largas com perfurações, ápices arredondados, sólidos e providos de pequenas cavidades. Nexina: lisa.

Dimensões. DP: $33,16 \mu \mathrm{m}(28-37 \mu \mathrm{m})$, DE: 31,36 $\mu \mathrm{m}$ (27-35 $\mu \mathrm{m})$, Razão DP/DE: 1,05.

\section{Pluchea laxiflora Hook. \& Arn. ex Baker}

(Figura 3A-H)

Descrição. Grãos de pólen médios, isopolares, radiossimétricos, prolato-esferoidais, âmbito circular, triangulares, tricolporados e espinhosos. Aberturas: três colporos bem visíveis, colpos grandes [largura 13,3 $\mu \mathrm{m}(12-15 \mu \mathrm{m})$, comprimento $23,9 \mu \mathrm{m}(20-25 \mu \mathrm{m})]$, de margens ornamentadas, extremidades arredondadas e endoabertura lalongada. Exina: espessa $[2,4 \mu \mathrm{m}(2-3 \mu \mathrm{m})]$, sexina maior que a nexina, separadas por uma cava, que aumenta de altura na região mediana do mesocolpo. Em MEV teto subpsilado e punctado. Sexina: tectada, endosexina mais robusta que a ectosexina. Endosexina em 2 séries, com columelas digitadas mais altas na base dos espinhos. Ornamentação constituída por espinhos [7,22 $\mu \mathrm{m}(5-9 \mu \mathrm{m})]$ grandes e robustos de bases largas com perfurações, ápice arredondado, sólidos providos de pequenas cavidades.

Dimensões. DP: 44,16 $\mu \mathrm{m}(33-60 \mu \mathrm{m})$, DE: 42,92 $\mu \mathrm{m}$ (32-59 $\mu \mathrm{m})$, Razão DP/DE: 1,02.

\section{DISCUSSÃO DOS RESULTADOS}

Grãos de pólen tricolporados, com exina espessa e espinhos são característicos de espécies entomófilas (Smith, 1990). No 

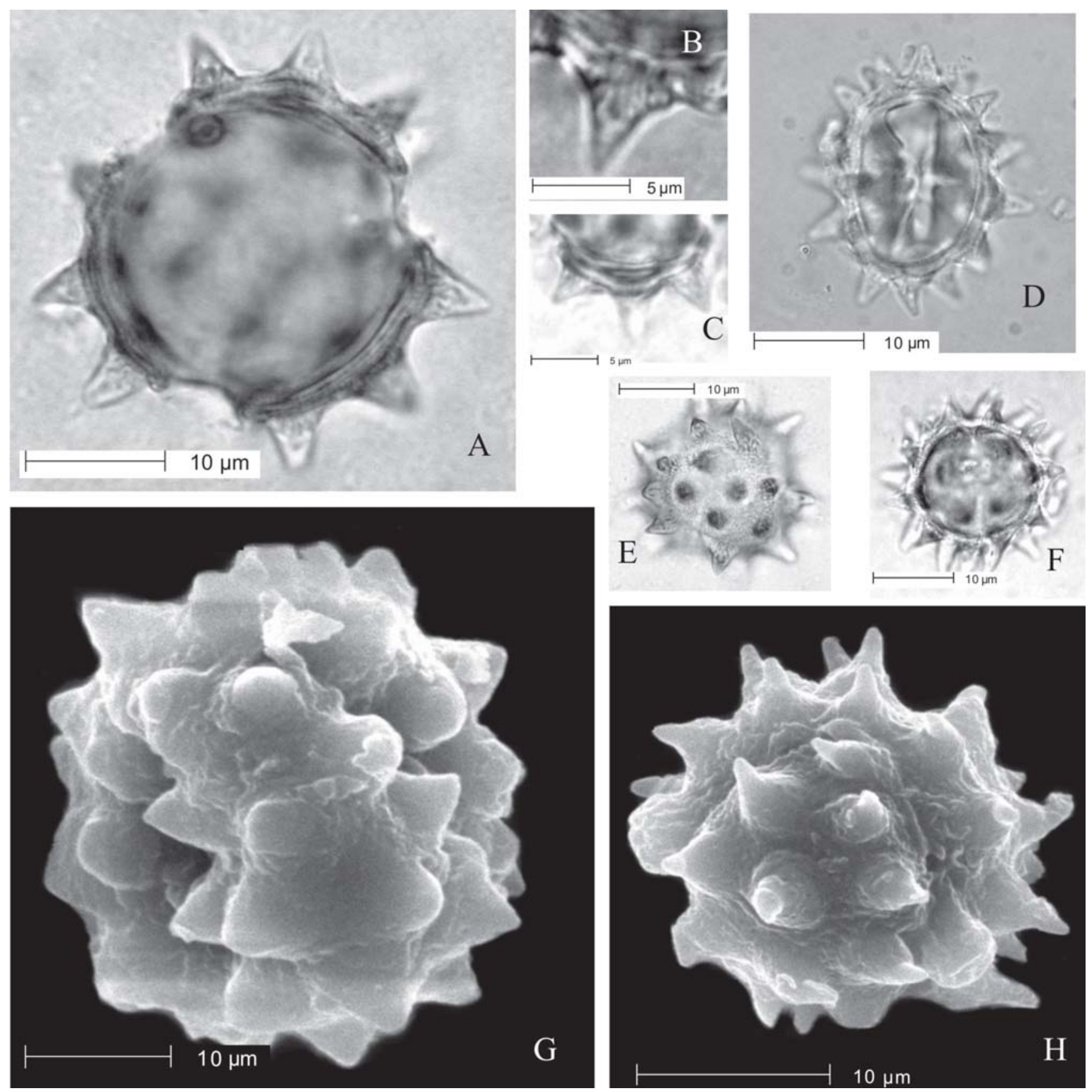

Figura 1. Pluchea oblongifolia. Entre parênteses o número da lâmina seguido da coordenada England Finder. A, Grão de pólen em vista polar (P159c, B586); B, Detalhe do espinho (P-159c, B598); C, Detalhe do mesocolpo, mostrando cava (P-159c, B598); D, Grão de pólen em vista equatorial (P-159c, B569); E, Aspecto geral da superfície do grão de pólen em vista polar (P159c, B586); F, Detalhe da endoabertura lalongada (P-159c, B570); G, Grão de pólen em vista equatorial, teto perfurado, sendo que as perfurações são maiores na base dos espinhos (MEV); H, Grão de pólen em vista equatorial (MEV).

Figure 1. Pluchea oblongifolia. In parenthesis the slide number followed by the England Finder coordinates. A, Pollen grain in polar view (P159c, B586); B, Spine in detail (P-159c, B598); C, Mesopolpium in detail, showing a cavea (P-159c, B598); D, Pollen grain in equatorial view (P-159c, B569); E, General aspects of surface of the pollen grain in polar view (P159c, B586); F, Lalongate endoaperture in detail (P159c, B586); G, Pollen grain in equatorial view, perforated tectum, the biggest perforations are at the spines' bases (SEM); H, Pollen grain in equatorial view.

entanto, a presença de cava nas três espécies analisadas pode ser um indício de tendência à anemofilia (Payne \& Skvarla, 1970). Segundo estes autores, a formação das cavas ocorre por perda de água quando o grão de pólen fica exposto ao ar. O processo de desidratação está relacionado aos espaços internos do grão de pólen (cavas, espaços interbaculares e exina esponjosa) os quais são, possivelmente, interconectados e se comunicam com o exterior através das cavidades basais dos espinhos e de outras pequenas perfurações na parede dos grãos (Salgado-Labouriau, 1982). 

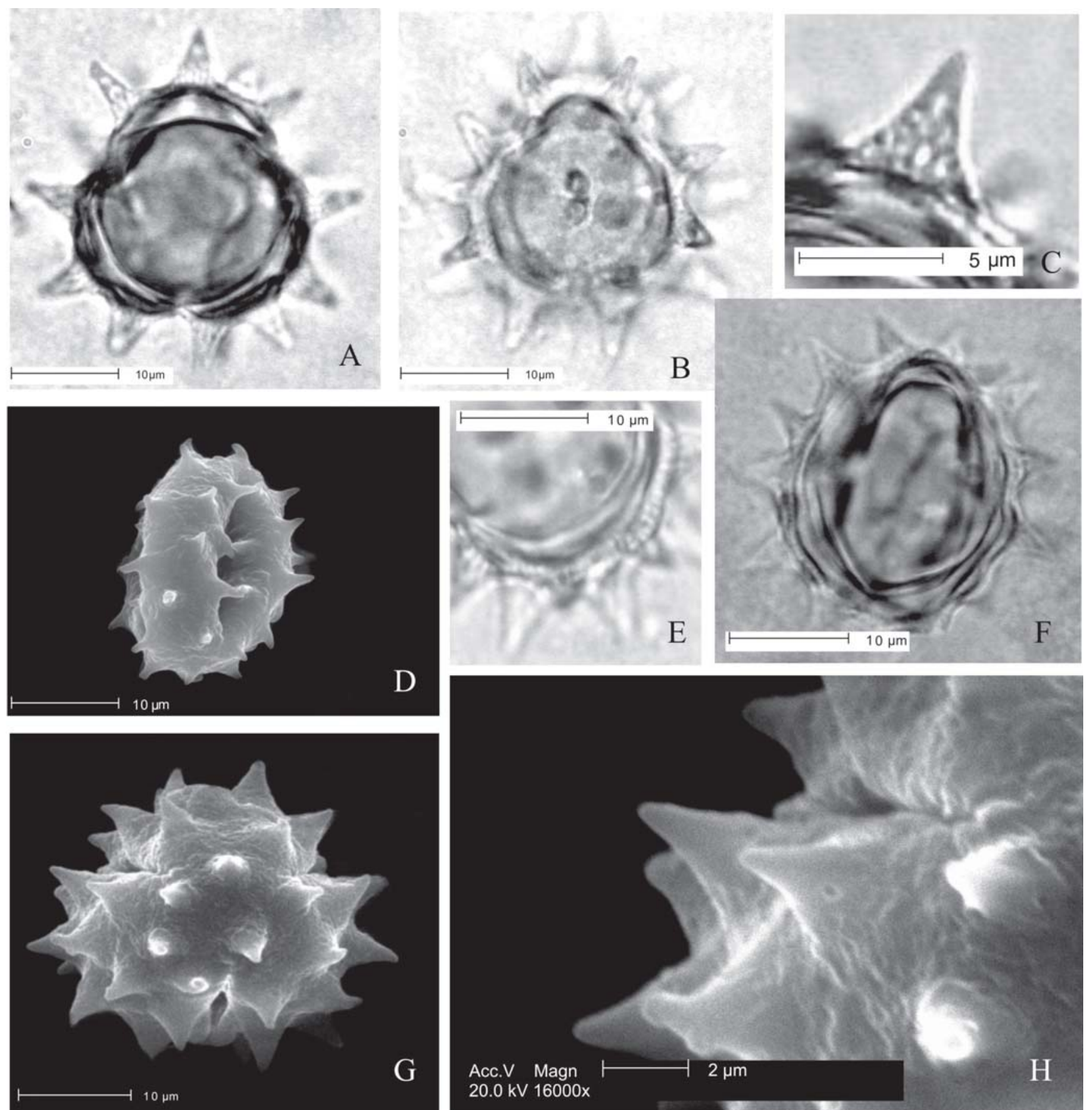

Figura 2. Pluchea sagittalis. Entre parênteses o número da lâmina seguido da coordenada England Finder. A, Grão de pólen em vista polar (P-161c, B476); B, Aspecto geral da superfície do grão de pólen em vista polar (P-161c, B476); C, Detalhe do espinho (P161c, B476); D, Grão de pólen em vista equatorial (MEV); E, Detalhe da cava na região do mesocolpo (P-161c, B506); F, Aspecto geral do grão de pólen em vista equatorial (P-161c, B446); G, Grão de pólen em vista polar (MEV); H, Detalhe do espinho com o teto perfurado (MEV).

Figure 2. Pluchea sagittalis. In parenthesis the slide number followed by the England Finder coordinates. A, Pollen grain in polar view (P-161c, B476); B, General aspects of surface of the pollen grain in polar view (P-161c, B476); C, Spine in detail (P-161c, B476); D, Pollen grain in equatorial view (SEM); $\mathbf{E}$, Detail of the cavea in the mesocolpium (P-161c, B506); $\mathbf{F}$, General aspects of the pollen grain in equatorial view (P-161C, B446); G, Pollen grain in polar view (SEM); H, Detail of the spine with perforated tectum (SEM).

As espécies estudadas mostram um padrão polínico homogêneo quanto ao tamanho, simetria e polaridade. No entanto, exibem diferenças na estrutura da exina, no tamanho da cava e da ornamentação. Pluchea laxiflora apresentou exina composta por duas séries columeladas na sexina enquanto Pluchea oblongifolia e Pluchea sagittalis apresentaram exina simples. P. oblongifolia possui cava menor que $1,0 \mu \mathrm{m}, P$. sagittalis apresentou cava com $2,0 \mu \mathrm{m}$ enquanto em $P$. laxiflora a cava mediu 5,0 $\mu \mathrm{m}$. Quanto à ornamentação, $P$. oblongifolia e $P$. sagittalis apresentaram 

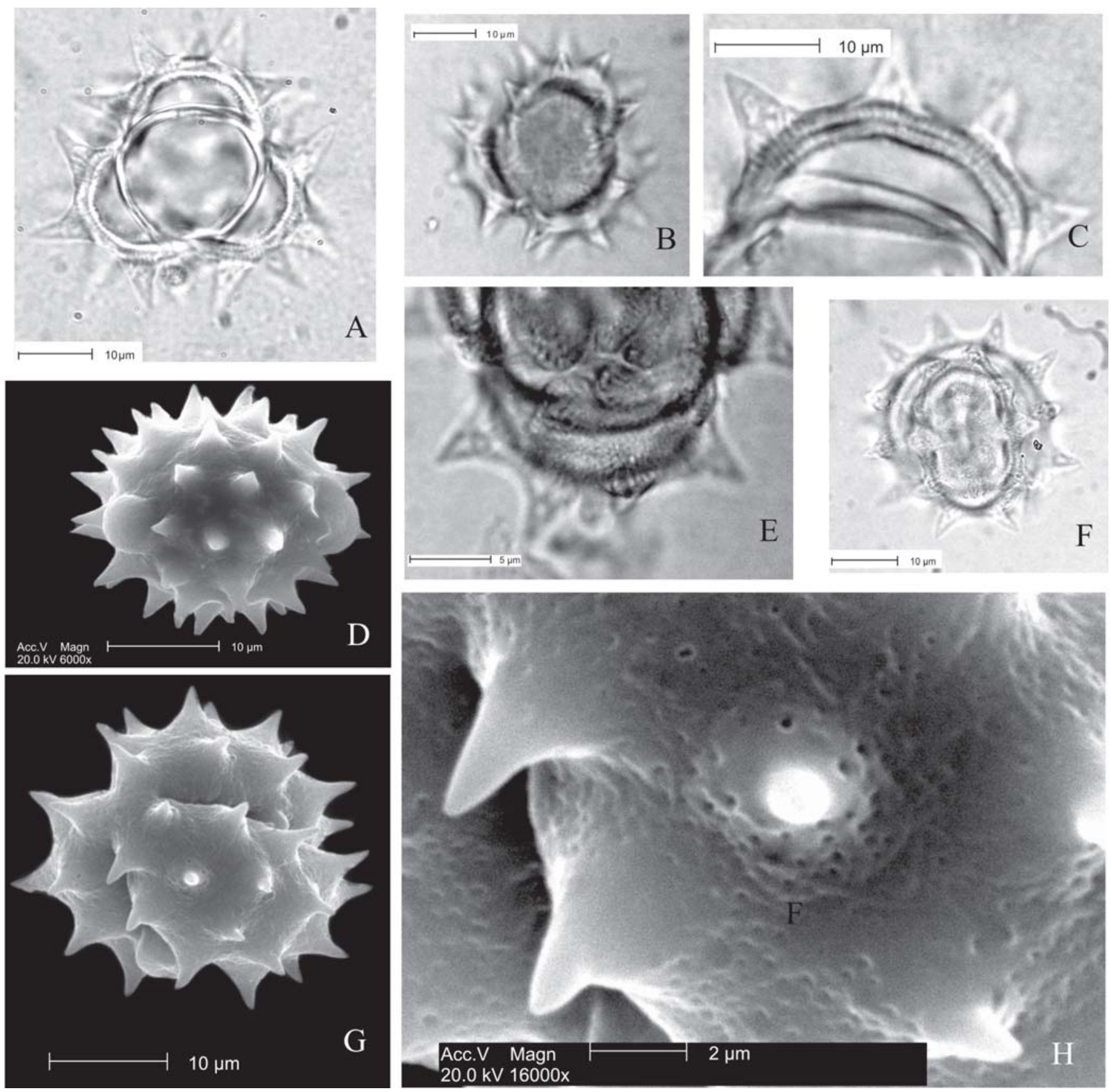

Figura 3. Pluchea laxiflora. Entre parênteses o número da lâmina seguido da coordenada England Finder. A, Grão de pólen em vista polar (P-160c, B685); B, Aspecto geral da superfície do grão de pólen em vista polar (P-160c, B685); C, Grão de pólen em vista polar, mostrando detalhe da sexina e cava (P-160c, B685); D, Grão de pólen em vista equatorial (MEV); E, Detalhe do mesocolpo, e espinho com columela digitada em vista polar (P-160c, B683); F, Vista equatorial (P-160c, B680); G, Detalhe do grão de pólen em vista polar, mostrando espinho circundado por outros 6 na região do mesocolpo (MEV); H, Detalhe da superfície com o teto perfurado sendo perfurações maiores na base dos espinhos (MEV).

Figure 3. Pluchea laxiflora. In parenthesis the slide number followed by the England Finder coordinates. A, Pollen grain in polar view (P-160c, B685); B, General aspects of surface of the pollen grain in polar view (P-160c, B685); C, Pollen grain in polar view, showing in detail the sexine and cavea (P-160c, B685); D, Pollen grain in equatorial view (SEM); E, Detail of the mesocolpium, and spine with digitate columellae in polar view (P-160c, B683); F, Equatorial view (P-160c, B680); G, Detail of the grain of pollen in polar view, showing spine surrounded for others 6 in the region of mesocolpium (SEM); $\mathbf{H}$, Detail of the spine with perforated tectum, the biggest perforations are at the spines' bases (SEM).

espinhos com ca. $5 \mu \mathrm{m}$ enquanto em $P$. laxiflora mediram aproximadamente $7 \mu \mathrm{m}$ (Quadro 1).

Grãos de pólen cavados, sexina com duas séries, sendo a externa baculada e a interna com perfurações mais ou menos regulares foram definidos como tipo polínico inulóide e são característicos da tribo Inuleae sensu lato. Com a divisão de Inuleae sensu lato nas subtribos Athrixiinae, Gnaphaliinae e Inulinae (Merxmüller et al., 1977), foi proposto o tipo polínico gnafalióide como padrão morfológico para a subtribo Gnaphaliinae (Anderberg, 
1989). O tipo gnafalióide difere do inulóide por apresentar a camada interna da parede menos regularmente perfurada. As subtribos Inuliinae e Pluchinae apresentam grãos com sexina baculada. Anderberg (1989) elevou as três subtribos, propostas por Merxmüleer et al. (1977), para tribos: Gnaphaliae, Inuleae (sem representantes no Brasil) e Plucheeae. Quanto à morfologia polínica, Anderberg (1989) praticamente manteve a proposição de Merxmüller et al. (1977), ou seja, a tribo Gnaphalieae apresenta grãos cavados e sexina com duas séries enquanto Inuleae e Plucheeae apresentam grãos com sexina simples.

Os padrões polínicos das três espécies de Pluchea ocorrentes no Rio Grande do Sul não podem ser considerados como inulóide nem gnafalióide, pois Pluchea oblongifolia e $P$. sagittalis apresentam exina simples. Por outro lado, $P$. laxiflora apresenta exina com duas camadas e não se enquadra no padrão proposto para Plucheae. Tampouco podem ser considerados como do tipo Gnaphalium (cujo gênero já pertenceu à mesma tribo de Pluchea), proposto por Salgado-Labouriau (1973), para Asteraceae do Cerrado, pois este tipo é espiculado, enquanto Pluchea é espinescente. Estudos polínicos realizados por Perveen (1999) consideraram as espécies Pluchea lanceolata (DC.) Oliv. e Pluchea arguta Boiss. como tipo polínico II [Eclipta prostata (L.) L.]. O autor, porém, não registra a presença de cavas para $P$. arguta e $P$. lanceolata.

\section{CONSIDERAÇÕES FINAIS}

As espécies de Pluchea que ocorrem no Rio Grande do Sul não puderam ser relacionadas a nenhum tipo polínico, tampouco estão contempladas nas características polínicas da tribo Plucheeae (sensu Andeberg, 1989). A finalização das análises polínicas dos demais gêneros da tribo fornecerá elementos adicionais para o estabelecimento de um possível tipo ou grupo polínico (Punt, 1971). Os dados obtidos até o momento, entretanto, permitem a diferenciação, a partir da morfologia polínica, das três espécies do gênero Pluchea, citadas para o Rio Grande do Sul.

\section{AGRADECIMENTOS}

Os autores agradecem ao Centro de Microscopia e Microanálise da ULBRA pelo apoio prestado, e a Nelson I. Matzenbacher e Sérgio A. de L. Bordignon, pelas valiosas discussões.

\section{REFERÊNCIAS}

Anderberg, A.A. 1989. Phylogeny and reclassification of the tribe Inuleae (Asteraceae). Canadian Journal of Botany, 67:2277-2296.

Bremer, K. 1994. Asteraceae: cladistics and classification. Portland, Timber Press, 752 p.

Bremer, K. \& Gustafsson, M.H.G. 1997. East Gondwana of the sunflower alliance of families. Proceedings of the National Academy of Sciences of the United States of America, 94:9188-9190.

Bürger, M.E.1995. Estudos farmacológicos do extrato da Pluchea sagittalis (Lam.) Cabr. sobre o trato gastrointestinal. Curso de Pós-graduação em Ciências e Tecnologia Farmacêutica, Universidade Federal de Santa Maria, Dissertação de Mestrado, 180 p.

Dalpiaz, S. \& Ritter, M.R. 1998. O gênero Pluchea Cass. (Asteraceae) no Rio Grande do Sul, Brasil: aspectos taxonômicos. Iheringia, Série Botânica, 50:3-20.

Erdtman, G. 1952. Pollen morphology and plant taxonomy. New York, Hafner Publishing Conpany, 553 p.

Hind, D.J.N. 1993. A checklist of Brazilian Senecioneae (Compositae). Kew Bulletin, 48(2):279-295.

Matzenbacher, I.N. 2003. Diversidade florística dos campos sul-brasileiros. In: CONGRESSO NACIONAL DE BOTÂNICA, 54, 2003. Boletim de Resumos, Recife, SBB, p.124-127.

Melhem, T.S.; Silvestre, M.S.F. \& Makino, H. 1979. Grãos de pólen de plantas alergógenas: Compositae. Boletim do Instituto de Botânica, 8:73-100.

Melhem, T.S.; Cruz-Barroas M.A.V.; Corrêa A.M.S.; MakinoWatanabe, H.; Silvestre-Capelato, M.S.F. \& Esteves, V.L.G. 2003. Variabilidade polínica em plantas de Campos de Jordão (São Paulo, Brasil). Boletim do Instituto de Botânica, 101 p.

Mendonça, C.B.F. \& Gonçalves-Esteves, V. 2000. Palinologia de espécies da tribo Eupatorieae (Compositae Giseke) ocorrentes na restinga de Carapebus, Carapebus: Rio de Janeiro. Revista Brasileira de Botânica, 23(2):195-205.

Mendonça, C.B.F.; Gonçalves-Esteves, V. \& Esteves, R.L. 2002. Palinologia de espécies de Asteroideae (Compositae) ocorrentes na restinga de Carapebus, Carapebus, Rio de Janeiro. Hoehnea, 29(3):233-240

Mendonça, C.B.F.; Gonçalves-Esteves, V.; Esteves, R.L. \& Gonçalves, N.R. 2003. Ultrastructure caracterization of the pollen grains of Lepidaploa R.M. King \& H. Rob. (VernonieaeCompositae). Acta Microscopica, 12:41-42.

Merxmüller, H.; Leins, P. \& Roessler, H. 1977. Inuleae-systematic review. In: V.H. Heywood; J.B. Harborne \& B.L. Turner (eds.) Biology and Chemistry of the Compositae, London, Academic Press, v. 1., p. 577-602.

Moreira, X.A. 1969. Catálogo de pólens do Estado da Guanabara e arredores. Rio de Janeiro, Museu Nacional, 48 p.

Payne, W.W. \& Skvarla, J.J. 1970. Electron microscope study of Ambrosia pollen (Compositae: Ambrosieae). Grana, 10:89-100.

Peçanha, A.F.; Mendonça, C.B.F. \& Gonçalves-Esteves, V.; Esteves, R.L. 2001. Palinotaxonomia de espécies de Piptocarpha R. Br. (Compositae, Vernonieae) do Estado do Rio de Janeiro. Boletim do Museu Nacional do Rio de Janeiro, 112:1-14.

Perveen, A. 1999. Contributions to the pollen morphology of the family Compositae. Turkian Journal of Biology, 23:523-535.

Punt, W. 1971. Pollen morphology of the genera Norantea, Souroubea and Ruyschia (Marcgraviaceae). Pollen et Spores, 13(2):199-232.

Punt, W.; Blackmores, S.; Nilsson, S. \& Le Thomas, A. 1994. Glossary of pollen and spore terminology. Utrecht, LPP Foundation, 71 p. (LPP Contributions Series No. 1).

Salgado-Labouriau, M.L. 1973. Contribuição à palinologia dos cerrados. Rio de Janeiro, Academia Brasileira de Ciências, 285 p.

Salgado-Labouriau, M.L. 1982. On cavities in spines of Compositae pollen. Grana, 21:97-102.

Salgado-Labouriau, M.L. 1983. Key to the Compositae pollen of the Northern Andes. Sociedade Venezolana de Ciências Naturales, 141:127-152.

Smith, E.G. 1990. Sampling and identifying allergenic pollens and 
molds. Texas, Blewstone Press, $196 \mathrm{p}$.

Stevens, P.F. (2001 onwards). Angiosperm Phylogeny Website. Version 5, May 2004 (and more or less continuously updated since). Disponível em <http://mobot.org/MOBOT/research/ APweb/>. Acesso: novembro 2004.

Venable, D.L. \& Levin, D.A. 1983. Morphological dispersal structures in relation to growth habit in the Compositae. Plant Systematic Evolution, 143:1-16.

Received in January, 2006; accepted in March, 2006.

Apêndice. Relação dos gêneros e espécies citados no texto.

Appendix. List of genera and species cited in the text.

Eclipta prostata (L.) L.

Pluchea arguta Boiss.

Pluchea lanceolata (DC.)

Pluchea laxiflora Hook. \& Arn. ex Baker

Pluchea oblongifolia DC.

Pluchea sagittalis (Lam.) Cabr. 